\title{
Estimativa do Consumo Voluntário do Capim-Tanzânia (Panicum maximum, Jacq. cv. Tanzânia) por Vacas em Lactação sob Pastejo Rotacionado ${ }^{1}$
}

\author{
Maria Lúcia Pereira Lima ${ }^{2,3}$, Telma Teresinha Berchielli, ${ }^{4,5}$, José Ramos Nogueira ${ }^{3}$, \\ Ana Cláudia Ruggieri ${ }^{5,6}$, Luiz Januário Magalhães Aroeira ${ }^{5,7}$, Ana Karina Dias Salman ${ }^{8}$, \\ João Paulo Guimarães Soares ${ }^{8}$
}

\begin{abstract}
RESUMO - O estudo foi conduzido numa área de capim-Tanzânia (Panicum maximum), manejada em pastejo rotacionado para estimar o consumo de matéria seca de vacas em lactação. Os três tratamentos foram: vacas mestiças alimentadas com $3 \mathrm{~kg}$ de concentrado e vacas mestiças e Zebu (Gir) sem suplementação com concentrado. Observou-se uma quantidade de 7340,2 kg de matéria seca (MS) /ha de forragem disponível antes da ocupação e de 5.639,5 após o $3^{\circ}$ dia de ocupação. O consumo de MS de capim-Tanzânia foi 8,26 \pm 5,66, $11,01 \pm 5,37$ e $9,55 \pm 2,31 \mathrm{~kg}$ de $\mathrm{MS} / \mathrm{vaca} / \mathrm{dia}$ ou $2,15 \%, 2,37 \%$ e 2,34\% do peso vivo, respectivamente para as vacas suplementadas, cruzadas não suplementadas e vacas Zebu . A média da produção de leite foi maior para o grupo suplementado (11,98 kg/vaca/dia). A produção de leite observada para as vacas não suplementadas foi similar. Produção de leite de 6,53 foi obtida pelas vacas cruzadas não suplementadas e 5,46 por vaca/dia foi produzida pelas vacas Zebu.
\end{abstract}

Palavras-chave: consumo de matéria seca, gado Gir, pastagem tropical, vacas mestiças

\section{Estimation of Voluntary Intake of Tanzania Grass (Panicum maximum, Jacq. cv. Tanzânia) Rotationally Grazed by Lactating Cows}

\begin{abstract}
The trial was carried out in a Tanzania grass (Panicum maximum) pasture, rotationally grazed by lactating cows, to estimate the dry matter intake. Three treatments were tested: crossbred cows fed $3 \mathrm{~kg}$ per day of concentrate and crossbred and Zebu cows (Gyr) without concentrate supplementation. The forage availability was 7,340.2 kg of dry matter (DM) /ha before and 5,639.5 after the $3^{\text {rd }}$ grazing day. The Tanzania grass DM intake was $8.26 \pm 5.66,11.01 \pm 5.37$ and $9.55 \pm 2.31 \mathrm{~kg}$ of DM/cow/day per day or $2.15,2.37$ and $2.34 \%$ of live weight, respectively, for the supplemented crossbred cows and non supplemented crossbred and Zebu cows. The average milk production was higher for the supplemented group (11.98 kg/cow/day). The milk production observed by the non supplemented cows was similar. Milk yield of 6.53 was obtained for non supplemented crossbred cows and $5.46 \mathrm{~kg}$ per cow/day was performed for the Zebu cows.
\end{abstract}

Key Words: crossbred cows, dry matter intake, Gyr cattle, tropical pasture

\section{Introdução}

O capim-Tanzânia é um cultivar de Panicum maximum, lançado em 1990 pelo Centro Nacional de Pesquisa com Gado de Corte (EMBRAPA). Em experimento realizado em Campo Grande, MS (Euclides et al., 1995, citado por CORSI e SANTOS, 1995) foi encontrada alta disponibilidade de forragem, suportando $4,7 \mathrm{UA} /$ ha. É uma forrageira bem adaptada a solos de baixa fertilidade, apresenta grande facilidade de manejo e responde bem à adubação (EUCLIDES et al., 1999).

O consumo de matéria seca das pastagens está diretamente ligado ao desempenho dos animais, porque determina a quantidade de nutrientes ingeridos, os quais são necessários para atender as exigências de manutenção e produção animal (GOMIDE, 1993).

$O$ apetite do animal é função da demanda de energia, que é determinada pelo potencial genético e estado fisiológico do animal (MERTENS, 1994). O efeito de espécies e de raças dentro da mesma espécie sobre a ingestão voluntária está relacionado com as diferenças entre a exigência nutricional para manutenção, a capacidade física do trato gastrointestinal e a composição do ganho de peso (KETELAARS e TOLKAMP, 1992).

\footnotetext{
1 Projeto parcialmente financiado pela FAPESP.

2 Estudante de pós-graduação - FCAV/Unesp - Jaboticabal, SP, bolsista do CNPq. E.mail: duluzoo@convex.com.br

${ }^{3}$ Pesquisador do Instituto de Zootecnia, Caixa Postal 206, 14001-970, Ribeirão Preto, SP.

${ }^{4}$ Professor da FCAV - Unesp - Jaboticabal, SP. E.mail: ttberchi@fcav.unesp.br

${ }^{5}$ Pesquisador do CNPq

${ }^{6}$ Pesquisador do Instituto de Zootecnia, Caixa Postal 60, 14160-000, Sertãozinho, SP.

${ }^{7}$ Pesquisador da Embrapa - Centro de Pesquisa de Gado leiteiro, Juiz de Fora, MG. E.mail: laroeira@cnpgl.embrapa.br

${ }^{8}$ Estudante de pós-graduação - FCAV/ Unesp - Jaboticabal, SP, bolsista da FAPESP
} 
Quanto ao efeito das características do alimento sobre o consumo, as gramíneas tropicais são menos consumidas quando comparadas às do clima temperado, o que está associado ao baixo teor de nitrogênio, baixa digestibilidade e altos teores de fibras e ao tempo de retenção das mesmas no rúmen. (Minson, 1980, citado por EUCLIDES et al. 1989). Segundo VAN SOEST (1994), concentrações de proteína bruta acima de 7\% não são bem correlacionadas com o consumo, porém abaixo desse nível, ocorre decréscimo na ingestão.

Além da composição química, a disponibilidade de forragem pode influenciar o consumo. Em pastagens, deve-se trabalhar numa situação de oferta de forragem não limitante, para avaliação consistente do consumo (MERTENS, 1994).

Com relação ao efeito da suplementação com concentrados protéicos sobre o consumo de pasto, VILELA et al. (1980) observaram ligeiro aumento no consumo de capim gordura, quando vacas mestiças foram suplementadas diariamente com $900 \mathrm{~g}$ de farelo de soja, no período das águas. No entanto, a suplementação com concentrado balanceado com farelo de soja e milho resultou na redução do consumo de pasto na ordem de $0,8 \mathrm{~kg}$ de matéria seca para cada $\mathrm{kg}$ de concentrado consumido, um ligeiro aumento na ingestão da matéria seca total e aumento de $0,3 \mathrm{~kg}$ de leite para cada $\mathrm{kg}$ de concentrado.

AROEIRA et al. (1999) não observaram efeito da suplementação de vacas mestiças, com $2,5 \mathrm{~kg}$ de concentrado, sobre o consumo de MS de capim elefante em diferentes estações do ano. No entanto, a ingestão de matéria seca total das vacas suplementadas foi significativamente $(\mathrm{P}<0,05)$ maior ( $3,0 \%$ do peso vivo) do que a das vacas não suplementadas ( $2,7 \%$ do peso vivo).

A estimativa do consumo voluntário de pasto a partir da relação entre a produção fecal e da indigestibilidade da forragem, com a utilização da extrusa na determinação da digestibilidade, aumenta a exatidão dos resultados por considerar a seletividade da dieta ingerida pelos animais (AROEIRA, 1997).

O objetivo do trabalho foi determinar o consumo voluntário do capim-Tanzânia por vacas da raça Gir e mestiças em lactação.

\section{Material e métodos}

O experimento foi desenvolvido no Núcleo de Pesquisas Zootécnicas Nordeste do Instituto de Zootecnia em Ribeirão Preto, SP, em uma área de latosolo roxo distrófico, levemente ondulado, em pastagens com sete anos de uso. Através da análise de solo encontrou-se $\mathrm{pH}$ de 5,2, matéria orgânica de $44 \mathrm{~g} / \mathrm{dm}^{3}$, fósforo de $18 \mathrm{mg} / \mathrm{dm}^{3}$, potássio de $2,0 \mathrm{mg} / \mathrm{dm}^{3}$, cálcio de $25 \mathrm{mmol} / \mathrm{dm}^{3}$, magnésio de $20 \mathrm{mmol} / \mathrm{dm}^{3}$ e hidrogênio mais alumínio de $38 \mathrm{mmol} / \mathrm{dm}^{3}$, saturação por bases de $47 \%$ e valor cultural de $55,3 \%$.

A área experimental de 15,82 ha era composta de 14 piquetes de 1,13 ha, formada de capim-Tanzânia (Panicum maximum Jacq. cv. Tanzânia), adubada com $150 \mathrm{~kg}$ de N/ha/ano. A média anual da lotação foi de 2,1 animais/ha.

Para avaliação do consumo voluntário de forragem foram utilizadas 24 vacas, com idade entre 3 e 9 anos, com ordem de lactação variando entre a primeira e sexta e, em média, com 6 meses de lactação, subdivididas em três grupos: um com oito vacas puras da raça Gir, somente alimentadas com pastagem, outro com oito vacas mestiças (Gir x Holandês), também em regime exclusivo de pasto, e outro com oito vacas mestiças (Gir x Holandês), que recebiam, além da forragem no pasto, $3 \mathrm{~kg}$ de concentrado. $\mathrm{O}$ concentrado oferecido era composto por $72,2 \%$ de milho, $25,3 \%$ de farelo de soja e $2,5 \%$ de minerais.

A estimativa do consumo de matéria seca (MS) do capim foi realizada a partir da produção de fezes (PFT) e digestibilidade in vitro da matéria seca (DIVMS) dos componentes da dieta, utilizando-se a seguinte equação:

$$
\text { Consumo }(\mathrm{kg} \text { de MS } / \text { dia })=\frac{\text { PFT }}{1-\text { DIVMS }}
$$

em que: PFT = produção fecal total de cada vaca em $\mathrm{kg}$ de MS fecal/dia; DIVMS = digestibilidade in vitro da matéria seca dos componentes da dieta.

A estimativa da produção fecal foi feita utilizando-se fibra em detergente neutro (FDN) mordentada com dicromato de sódio. Anteriormente ao início do experimento, coletou-se extrusa, utilizando-se vacas fistuladas no esôfago. Parte do material foi seca em estufa com circulação forçada de ar a $55^{\circ} \mathrm{C}$, armazenada para posterior determinação de digestibilidade in vitro da matéria seca. O restante da extrusa foi fervido em panela de alumínio com detergente neutro comercial (100 $\mathrm{mL}$ para cada $\mathrm{kg}$ de extrusa), durante 3 horas, para extração da FDN. Após descanso de uma noite, o material foi lavado em água corrente, seco em estufa com circulação forçada de ar a $55^{\circ} \mathrm{C}$ por 24 horas e, posteriormente tratado com dicromato de sódio $\left(\mathrm{Na}_{2} \mathrm{Cr}_{2} \mathrm{O}_{7} \mathrm{H}_{2} \mathrm{O}\right)$ para produção de $\mathrm{FDN}$ 
mordentada, segundo metodologia descrita por COLUCCI (1984).

O experimento foi realizado durante o mês de janeiro e teve um período experimental de 5 dias. Cada vaca recebeu, em média, $30 \mathrm{~g}$ de FDN mordentada, distribuídos em 10 balas confeccionadas em papel toalha, em dose única, via oral e com auxílio de sonda. O fornecimento do marcador foi feito entre $6 \mathrm{~h} 30 \mathrm{e} 9 \mathrm{~h}$ no primeiro dia do experimento. A colheita de fezes foi feita diretamente no reto às $6,9,12,24,32,36,48,56,72,80,96,104$, e 120 horas após a administração das cápsulas. As curvas de excreção fecal foram traçadas para cada vaca a partir da concentração de cromo nas fezes amostradas nos diferentes horários, conforme modelo de POND et al. (1989):

$$
Y=\frac{K o L_{1}(t-\theta) e^{-(L 1-\theta)}}{0,59635}
$$

em que: $\mathrm{Y}=$ concentração do marcador; $\mathrm{K}_{0}=$ concentração do marcador quando é misturado instantaneamente no compartimento; $\mathrm{L}_{1}=$ parâmetro da taxa de passagem; $t$ = tempo após a administração do marcador; $\theta=$ tempo decorrido até o primeiro aparecimento do marcador nas fezes.

A produção fecal total (PFT) diária foi calculada com base na seguinte relação:

$$
\operatorname{PFT}(\mathrm{g} \text { MS } / \text { dia })=\frac{\text { marcador administrado }(\mu \mathrm{g})}{\mathrm{K}_{\mathrm{o}}(\mu \mathrm{g} / \mathrm{gMS}) \mathrm{K}_{1} \bullet 24}
$$

em que: $\mathrm{K}_{0}=$ concentração do marcador quando é misturado instantaneamente no compartimento; $\mathrm{K}_{1}=$ taxa de passagem no rúmen da fração sólida do conteúdo ruminal.

$\mathrm{Na}$ mesma época experimental foi realizada a estimativa da disponibilidade do pasto, na entrada e saída dos animais do piquete, por intermédio do método do quadrado, utilizado por VILELA et al. (1996). Todo material coletado foi devidamente identificado e pesado, sendo separado nas respectivas frações de colmos, folhas e material morto. Em seguida, foram secos em estufa de ventilação forçada $55^{\circ} \mathrm{C}$, durante 48 horas, sendo posteriormente realizados os cálculos de disponibilidade de MS.

As análises laboratoriais foram realizadas no Laboratório de Nutrição Animal do Departamento de Zootecnia daFaculdade de Ciências Agrárias e Veterinárias, UNESP, Jaboticabal, SP. Para determinação do cromo das amostras de fezes e de FDN mordentada com dicromato, utilizou-se o método de WILLIANS et al. (1962).

A análise estatística foi feita pelo SAS (1992), utilizando-se o delineamento inteiramente casualizado, com análise de covariância, em função da ordem de lactação das vacas (BANZATTO e KRONKA,1992).

\section{Resultados e Discussão}

A disponibilidade de forragem ofertada antes da entrada dos animais e a residual (após a ocupação do piquete), assim como as proporções de folhas, colmos e material morto, podem ser observada na Tabela 1. A disponibilidade de forragem observadas antes da entrada dos animais foi similar à observada por CECATO et al. (1996), de $7441 \mathrm{~kg}$ de matéria seca/ha, para um ciclo de pastejo de 35 dias, e maior do que a observada por SANTOS et al. (1999), de $5772 \mathrm{~kg}$ de matéria seca/ha, para um ciclo de pastejo de 38 dias.

No mês de janeiro, a relação folha:caule foi de 2,06 antes da entrada dos animais e de 1,27 após a ocupação do piquete. SANTOS et al. (1999) encontraram relação folha:caule inferior em pastagens de capim-Tanzânia, amostradas nos meses de janeiro e fevereiro, isto é, encontraram relações de 1,17,1,10 e

Tabela 1 - Disponibilidade de forragem antes do $1^{\circ}$ dia e após o $3^{\circ}$ dia de ocupação do piquete e a proporção de folha, caule e material morto, em janeiro

\begin{tabular}{|c|c|c|c|c|}
\hline & $\begin{array}{l}\text { Massa bruta de forragem } \\
\text { (kg de MS/ha) } \\
\text { Total pasture mass } \\
\text { (kg of DM/ha) }\end{array}$ & $\begin{array}{l}\text { Folha (\%) } \\
\text { Leaf (\%) }\end{array}$ & $\begin{array}{c}\text { Caule }(\%) \\
\text { Stem (\%) }\end{array}$ & $\begin{array}{c}\text { Material morto (\%) } \\
\text { Dead material (\%) }\end{array}$ \\
\hline $\begin{array}{l}\text { Antes do } 1^{\mathrm{o}} \text { dia } \\
\text { Before } 1^{\text {st }} \text { day }\end{array}$ & 7340,2 & 62 & 30 & 8 \\
\hline $\begin{array}{l}\text { Após o } 3^{\circ} \text { dia } \\
\text { After } 3^{\text {rd day }}\end{array}$ & 5639,5 & 47 & 37 & 16 \\
\hline
\end{tabular}

Table 1 - Forage availability before the $1^{\text {st }}$ day and after the $3^{\text {rd }}$ day occupation paddock and the proportion of leaves, stem and dead material, in January 
1,05 para ciclo de pastejo de 28,38 e 48 dias.

A composição bromatológica e digestibilidade in vitro da matéria seca da extrusa e do concentrado, podem ser observados na Tabela 2 .

Os resultados referentes ao peso vivo, ingestão diária da matéria seca de capim e de concentrado, assim como a relação entre a ingestão de matéria seca e o peso vivo, em porcentagem, para os três grupos experimentais, estão na Tabela 3.

As vacas mestiças apresentaram peso vivo maior $(\mathrm{P}<0,01)$ do que as vacas da raça Gir, mas não houve diferença para o consumo de matéria seca de capim entre as vacas, assim como para o total de matéria seca ingerida. No entanto, o fornecimento de $3 \mathrm{~kg}$ de concentrado por vaca/ dia provocou redução de $24,5 \%$ no consumo de capim, quando se considerou a ingestão total de matéria seca e de 33,3\% quando se considerou o consumo em relação ao peso vivo. Observouse também alto valor para o desvio padrão da média nos três tratamentos.
Também não foi encontrada diferença significativa para consumo de matéria seca em relação ao peso vivo entre os três grupos experimentais. Diferentemente desses resultados, FURLAN (1998), trabalhando em quatro épocas do ano, verificou um consumo médio de matéria seca maior para as vacas mestiças do que para as vacas Gir (1,58 e 1,38\% do peso vivo) em pastagem de capim-coastcross. Durante o mês de janeiro, o consumo de capim, em relação ao peso vivo, foi menor ao encontrado neste trabalho, isto é, de $0,95 \%$ para as vacas Gir e 1,14\% para as mestiças.

EUCLIDES et al. (1999), trabalhando com novilhos, estimaram o consumo médio de matéria seca de capim-Tanzânia, na época da seca e das águas de $2,46 \%$. Durante o mês de fevereiro, esses autores encontraram média de $2,65 \%$ do peso vivo, resultado superior ao deste experimento.

MADSEN et al. (1997) assumem que a ingestão potencial de pastagem está relacionada com a fibra

Tabela 2 - Composição e digestibilidade in vitro da matéria seca da forragem coletada em animais fistulados no esôfago (extrusa) e do concentrado, em janeiro

Table 2 - Composition and in vitro dry matter digestibility (IVDMD) of grass collected from esophageal fistulated animal (extrusa) and from concentrate, in January

\begin{tabular}{|c|c|c|c|c|c|c|}
\hline & & & $\begin{array}{l}\text { matéric } \\
\text { f dry mo }\end{array}$ & & & \\
\hline & MS (\%) & PB & FDN & FDA & Cinzas & DIVMS \\
\hline & $D M(\%)$ & $C P$ & $N D F$ & $A D F$ & Ash & $I V D M D$ \\
\hline $\begin{array}{l}\text { Extrusa } \\
\text { Extrusa }\end{array}$ & 13,8 & 12,1 & 78,8 & 42,6 & 5,9 & 66,5 \\
\hline $\begin{array}{l}\text { Concentrado } \\
\text { Concentrate }\end{array}$ & 88,7 & 19,9 & 27,0 & 5,8 & - & 97,5 \\
\hline
\end{tabular}

MS = matéria seca, $\mathrm{PB}$ = proteína bruta, FDN = fibra em detergente neutro, FDA = fibra em detergente ácido, DIVMS = Digestibilidade in vitro da matéria seca.

$D M=$ dry matter, $C P=$ crude protein, $N D F=$ neutral detergent fiber, $A D F=$ acid detergent fiber, $I V D M D=$ in vitro dry matter digestibility.

Tabela 3 - Peso vivo (PV), ingestão da matéria seca (IMS) do capim e do concentrado (Conc.) e relação entre a ingestão de matéria seca e o peso vivo, em porcentagem (\%PV) para os três grupos experimentais: mestiças com concentrado (1), mestiças sem concentrado (2) e Gir sem concentrado (3), em janeiro

Table 3 - Cows live weight ( $L W$ ), grass (DMI) and concentrate dry matter intake (Conc.) in $\mathrm{kg}$ and \% of the $L W$ of the three experimental group: crossbred with concentrate (1), crossbred without concentrate (2) and Gyr without concentrate (3), in January

\begin{tabular}{|c|c|c|c|c|c|c|c|}
\hline \multirow{2}{*}{$\begin{array}{l}\text { Grupos experimentais } \\
\text { Experimental } \\
\text { groups }\end{array}$} & \multirow[t]{2}{*}{$\begin{array}{c}\mathrm{PV}(\mathrm{kg} / \mathrm{vaca}) \\
L W(\mathrm{~kg} / \mathrm{cow})\end{array}$} & \multicolumn{3}{|c|}{$\begin{array}{l}\text { IMS } \\
D M I\end{array}$} & \multicolumn{3}{|c|}{$\begin{array}{l}\% \mathrm{PV} \\
\% L W\end{array}$} \\
\hline & & $\begin{array}{l}\text { Capim } \\
\text { Grass }\end{array}$ & $\begin{array}{l}\text { Conc. } \\
\text { Conc. }\end{array}$ & Total & $\begin{array}{l}\text { Capim } \\
\text { Grass }\end{array}$ & $\begin{array}{l}\text { Conc. } \\
\text { Conc. }\end{array}$ & Total \\
\hline 1 & $504^{\mathrm{a}}$ & $8,26^{a} \pm 5,66$ & 2,59 & $10,85^{\mathrm{a}}$ & 1,63 & 0,52 & $2,15^{\mathrm{a}}$ \\
\hline 2 & $495^{\mathrm{a}}$ & $11,01^{\mathrm{a}} \pm 5,37$ & - & $11,01^{\mathrm{a}}$ & 2,37 & - & $2,37^{a}$ \\
\hline 3 & $418^{b}$ & $9,55^{\mathrm{a}} \pm 2,31$ & - & $9,55^{\mathrm{a}}$ & 2,34 & - & 2,34 \\
\hline
\end{tabular}

a,b Médias, na mesma coluna, seguidas de letras diferentes, são diferentes $(P<0,01)$ pelo teste de Tukey.

$a, b$ Means, in the same column, followed by different letters are different $(P<.01)$ by Tukey test. 
em detergente neutro (FDN) presente na pastagem, ou seja, cada animal deve ingerir por dia $1,2 \%$ do peso vivo de FDN. Calculando-se o consumo de pastagem (considerando $1,2 \%$ do peso vivo de FDN) encontrou-se 7,42, 7,37 e 5,77 kg de matéria seca por animal/ dia para vacas mestiças que receberam suplementação de concentrado, para vacas mestiças que não receberam o concentrado e para vacas Gir, respectivamente. Esses valores são inferiores ao estimado pela produção de fezes que podem ser observados na Tabela 3. FURLAN (1998) também encontrou valores subestimados para consumo total de matéria seca quando utilizou o cálculo sugerido por MADSEN et al. (1997).

De qualquer forma, o valor de FDN encontrado para a extrusa foi bastante alto $(78,8 \%)$ e pode ter limitado o consumo de matéria seca, pois VAN SOEST (1994) afirmou que valores acima de 55 a $60 \%$ de FDN na matéria seca limitam o consumo de forragem.

$\mathrm{Na}$ Tabela 4 podem ser observados os valores referentes à produção de leite, ingestão de nutrientes e comparação com as exigências nutricionais segundo NRC (1989). Houve efeito significativo $(\mathrm{P}<0,05)$ da suplementação com concentrado sobre a produção de leite de vacas mestiças, verificando-se aumento de aproximadamente $1,82 \mathrm{~kg}$ de leite para cada $\mathrm{kg}$ de concentrado fornecido. Essa resposta à suplementação foi superior ao valor de $0,3 \mathrm{~kg}$ de leite por $\mathrm{kg}$ de concentrado, observado por VILELA et al. (1980) em pastagem

Tabela 4 - Produção de leite, ingestão de proteína bruta (PB) e nutrientes digestíveis totais (NDT) e exigências nutricionais, por vaca por dia, para os três grupos experimentais: mestiças com concentrado (1), mestiças sem concentrado (2) e Gir sem concentrado (3)

Table 4 - Milk production, intake of crude protein (CP) and total digestible nutrients (TDN) and nutrients requirements estimated for the three experimental group: crossbred with concentrate (1), crossbred without concentrate (2) and Gir without concentrate (3)

\begin{tabular}{|c|c|c|c|c|c|c|c|}
\hline \multirow[t]{3}{*}{$\begin{array}{l}\text { Grupos experimentais } \\
\text { Experimental groups }\end{array}$} & \multirow[t]{3}{*}{$\begin{array}{l}\text { Leite }(\mathrm{kg}) \\
\text { Milk }(\mathrm{kg})\end{array}$} & \multicolumn{2}{|c|}{$\begin{array}{l}\text { Ingestão (kg) } \\
\text { Intake (kg) }\end{array}$} & \multicolumn{2}{|c|}{$\begin{array}{l}\text { Exigência (kg) } \\
\text { Requirements (kg) }\end{array}$} & \multicolumn{2}{|c|}{$\begin{array}{l}\text { Diferença }(\mathrm{kg}) \\
\text { Difference }(\mathrm{kg})\end{array}$} \\
\hline & & PB & NDT* & PB & NDT & PB & NDT \\
\hline & & $C P$ & $T N D$ & $C P$ & $T N D$ & $C P$ & $T N D$ \\
\hline 1 & $11,98^{\mathrm{a}}$ & 1,54 & 8,17 & 1,41 & 7,43 & $+0,13$ & $+0,74$ \\
\hline 2 & $6,53^{\mathrm{a}}$ & 1,41 & 7,74 & 0,93 & 5,75 & $+0,48$ & $+1,99$ \\
\hline 3 & $5,46^{\mathrm{b}}$ & 1,13 & 6,22 & 0,74 & 4,66 & $+0,39$ & $+1,56$ \\
\hline
\end{tabular}

a,b Médias, na mesma coluna, seguidas de letras diferentes, são diferentes $(P<0,05)$ pelo teste de Tukey.

** Estimado a partir da IMSxDIVMS.

** NRC (1989).

a,b Means, in the same column, followed by different letters are different $(P<.05)$ by Tukey test.

** Estimated from DMIXDMIVD.

** NRC(1989).

de capim-gordura (Melinis minutiflora) e superior à variação entre 0,5 e $1,5 \mathrm{~kg}$ de leite por $\mathrm{kg}$ de concentrado citada por GOMIDE (1993) para vacas em pastagens.

\section{Conclusões}

As vacas mestiças e puras da raça Gir não diferiram quanto à ingestão voluntária de capimTanzânia.

O fornecimento de concentrado provocou redução no consumo de capim, indicando haver um efeito substituição do consumo da pastagem pelo concentrado.

\section{Referências Bibliográficas}

AROEIRA, L.J.M. Estimativas de consumo de gramíneas tropicais. In: TEIXEIRA, J.C. (Ed.) 1997. Digestibilidade em ruminantes. Lavras: UFLA/FAEP. p.127-163.

AROEIRA, L.J.M., LOPES, F.C.F., DERESZ, F. et al. 1999. Pasture availability and dry matter intake of lacting crossbred cows grazing elephant grass (Pennisetum purpureum, Schum.). Anim. Feed Sci. Technol., 78(1-2):313-324.

BANZATTO, D.A., KRONKA, S.N. 1992. Experimentação Agricola. Jaboticabal: FUNEP. 247p.

CECATO, U., BARBOSA, M.A.A.F., SAKAGUITI, E.S., et al. Avaliação de cultivares de Panicum maximum Jacq In: REUNIÃO ANUAL DA SOCIEDADE BRASILEIRA DE ZOOTECNIA, 33, 1996, Fortaleza. Anais... Fortaleza: SBZ, 1996. p.109-11.

COLUCCI, P.E. Comparative digestion and digesta kinetics in 
sheep and cattle. Ghelph: University of Ghelph, 1984.231p. Theses (PhD) - University of Ghelph, 1984.

CORSI, M., SANTOS, P.M. 1995. Potencial de produção do Panicum maximum. In: SIMPOSIO SOBRE MANEJO DE PASTAGEM, 12, 1995, Piracicaba. Anais... Piracicaba: FEALQ, 1995. p.275-304.

EUCLIDES, V.P.B., ZIMER, A.H., VIEIRA, J.M. Equilíbrio na utilização da forragem sob pastejo. In: SIMPÓSIO SOBRE ECOSSISTEMAS DE PASTAGENS, 1989, Jaboticabal. Anais... Jaboticabal: FCAV-UNESP, 1989. p.271-313.

EUCLIDES, V.P.B., THIAGO, L.R.L.S., MACEDO, M.C.M. et al. 1999. Consumo voluntário de forragem de três cultivares de Panicum maximum sob pastejo. R. Soc. Bras. Zootec., 28(6):1177-85.

FURLAN, C.L.F. Estimativas da disponibilidade da forragem, composição da extrusa e consumo de matéria seca de vacas em lactação sob pastejo intensivo de capim-coastcross (Cynodon dactylon (L.) Pers). Jaboticabal, SP:UNESP, 1998. 75p. Dissertação (Mestrado em Zootecnia) Faculdade de Ciências Agrárias e Veterinárias, Universidade Estadual Paulista, 1998

GOMIDE. J. 1993. A. Produção de leite em regime de pasto. R. Soc. Bras. Zootec., 22(4):591-613.

KETELAARS, J.J.M.H., TOLKAMP, B.J.1992. Toward a new theory of feed intake regulation in ruminants 1 . Causes of differences in voluntary feed intake: critique of current views. Livest. Prod. Sci., 30(4):269-96

MADSEN, J., HAVELPLUND, T., WEISBJERG, M.R. 1997 Appropriate methods for evaluation of tropical feeds for ruminants. Anim. Feed Sci. Techol., 69(1-3):53-66

MERTENS D.R. 1994. Regulation of forage intake. In: FAHEY JR., D.C. (Ed.) Forage quality, evaluation and utilization. Madison: American Society of Agronomy. p.450-492.
NATIONAL RESEARCH COUNCIL - NRC. 1989. Nutrients requirement of dairy cattle. 6 .ed. Washington, DC. $158 \mathrm{p}$.

POND, K.R., ELLIS, W.C., MATIS, J.H. et al. 1989. Passage of chromium-mordanted and rare earth-labeled fiber: time of dosing kinetics. J. Anim. Sci., 67(4):1020-28.

SANTOS, P.M., CORSI, M. BALSALOBRE, M.A.A. 1999. Efeito da freqüência de pastejo e da época do ano sobre a produção e a qualidade em Panicum maximum cvs Tanzânia e Mombaça. R. Soc. Bras. Zootec., 28(2):244-249.

SAS USERS GUIDE: STATISTICS. Cary, SAS Institute Inc., 1992. $965 \mathrm{p}$.

VAN SOEST, P.J. 1994. Nutritional ecology of the ruminant. 2.ed. Ithaca: Cornell University, Ithaca. 476p.

VILELA, D. ALVIM, M.J., CAMPOS, O.F. et al. 1996. Produção de leite de vacas holandesas em confinamento ou em pastagem de coastcross. R. Soc. Bras. Zootec., 25(6):1228-1244.

VILELA, H., CARDOSO, R.M., SILVA, J.F.C., GOMIDE, J.A.1980 Efeito da taxa de lotação e da alimentação suplementar sobre a produção de leite durante o período das chuvas. R. Soc. Bras. Zootec., 9(2):214-32.

WILliANS, C.H., DAVID, D.J., ISMA, O. 1962. The determination of chromic using absorption spectrophotometer. J. Agric. Sci., 59(3):381-385. 